\title{
Discussion on the Teaching Reform of Analytical Chemistry in Universities
}

\author{
Wenjie Zhao \\ Inner Mongolia University, 010021
}

\begin{abstract}
Because the analytical chemistry course covers a wide range of subject areas, and has higher requirements for students' practical ability, speculative awareness and thinking ability, how to improve the quality of classroom teaching activities to quickly improve the quality of students' learning becomes Many colleges and universities teachers need to focus on solving problems. This article discusses the specific ways of reforming analytical chemistry classrooms in colleges and universities from multiple perspectives, and hopes to provide references for other teachers.
\end{abstract}

Keywords: Higher Education; Analytical Chemistry Class; Concrete Way; Reform Strategy

Analytical chemistry is highly professional, and involves a variety of professional knowledge content such as chemical engineering, biology, pharmacy, metallurgy, and agriculture. Therefore, students are required to master basic knowledge and professional skills. The application of knowledge and application to solve problems, and then under the guidance of higher scientific research spirit, can grow into high-quality talents that meet the needs of national development. This requires teachers of colleges and universities to be able to keep pace with the times, and under the guidance of the continuous and in-depth improvement of educational reform concepts, to innovate in teaching work, so as to promote students in the construction of analytical chemistry classrooms that are more in line with students' learning needs. The purpose of all-round development.

\section{Innovate teaching content combined with industry development}

Many teachers in colleges and universities are seriously constrained by traditional educational concepts when they teach analytical chemistry, and they focus their teaching on the basis of explaining theoretical knowledge. This will not only seriously inhibit students' learning subjectivity, but also neglect to exercise their practical ability training process, so that students cannot have professional abilities that are in line with the development prospects of the industry, which will cause serious obstacles to their future employment. Therefore, teachers should not blindly explain the knowledge of analytical chemistry according to the content of the textbooks, but need to combine the current development of the industry and enrich the teaching content in a targeted manner. This will not only help students in the process of class A lot of industry information is also in the process of enriching its knowledge reserves to promote the better development of students.

Therefore, when teachers carry out analytical chemistry teaching activities, they should arrange the overall teaching content to lead students to explain chemical analysis knowledge and improve instrumental analysis skills. It is hoped that students can combine theoretical knowledge and practical ability to ensure that Rapid improvement of academic performance. With the continuous development of society, the content of instrument analysis is constantly innovating. In addition to learning the use and structure of conventional instruments, students also need to be able to learn the most cutting-edge and latest instrument structure at this stage. At this stage, the overall teaching goal of chemical analysis is mainly to require students to process, integrate and analyze samples with high efficiency and high quality. Although

Copyright (@) 2020 Wenjie Zhao

doi: $10.18282 /$ le.v9i7.1498

This is an open-access article distributed under the terms of the Creative Commons Attribution Non-Commercial License

(http://creativecommons.org/licenses/by-nc/4.0/), which permits unrestricted non-commercial use, distribution, and reproduction in any medium, provided the original work is properly cited. 
the traditional chemical analysis classroom is not focused on this, teachers can effectively extend the teaching content through the reform of the classroom teaching content, so that the classroom teaching content can change more closely with the times, so that students can learn in line with the development of the job requirements Knowledge and skills. This not only can fully mobilize students' learning initiative, but also the analytical chemistry class that is in line with professional development can also enable students to grasp the development prospects of the industry in time, and then formulate a more complete development plan for future learning activities to ensure future employment. The smooth progress.

\section{Actively innovate teaching ideas and innovative teaching methods}

Because the content of analytical chemistry teaching requires students to master more knowledge points and is highly professional, many teachers often use indoctrination methods to complete their knowledge in order to ensure the progress of the teaching. Many students are unable to generate the enthusiasm to participate in classroom knowledge in the too boring learning process, and at the same time they are unable to exert their dominant position in the classroom, they cannot generate the enthusiasm to actively complete the knowledge learning, which seriously hinders the improvement of learning quality. This requires teachers to combine the ever-changing developmental background of the higher education system and make targeted innovations in classroom teaching methods. This can not only ensure the smooth development of the teaching work, but also enable students to accumulate experience and exercise professional skills in a variety of classroom learning content, so as to grow into high-quality talents that meet the requirements of national development.

The use of information technology has brought new development vitality to different industries. Therefore, when teachers carry out analytical chemistry teaching activities, in order to ensure the high-quality development of teaching reform, they can enrich the teaching methods through the introduction of multimedia technology to achieve the purpose of attracting students' learning motivation. Because college students have a strong ability to explore, teachers can use the collection of Internet materials to build a clearer knowledge system for explaining some knowledge content, so that students can fully mobilize their desire to explore. In this way, students can intuitively understand the key content that needs to be mastered while watching the multimedia courseware, so as to formulate a more efficient learning plan according to their actual learning situation. In addition, because analytical chemistry has high requirements for students' inquiry ability, in order to change students' bad habit of relying on teachers to complete learning activities, teachers can introduce micro-class videos to encourage students to consciously master basic knowledge before class. This not only enables students to mobilize learning initiative in a more diverse classroom learning environment, but also fully demonstrates the analytical chemistry teaching of students' classroom subjectivity. It also makes it easier for students to ensure the extension of their thinking consciousness and the application of innovative abilities. Rapid improvement of learning efficiency.

\section{Concluding remarks}

In order to promote the high-efficiency development of analytical chemistry classrooms, teachers of higher education institutions need to combine the current teaching actual conditions, and in the ever-changing education system reform wave, firmly grasp the speculative consciousness, professional learning ability and knowledge structure characteristics of college students. In order to find an effective entry point for teaching reform. In this way, the teaching content can not only meet the learning needs of students, but also indicate the future development direction for students in teaching activities that are combined with the development prospects of the industry. In addition, more attention is paid to the analytical chemistry class that combines students' professional knowledge reserves and practical skills to meet the needs of social positions for analytical chemistry talents and lay a solid foundation for students to better participate in employment in the future. 


\section{References}

1. Liu Rui, Song Yafang, Li Song, Luo Xuan. From the perspective of students, explore the problems and improvement of teaching methods in the instrumental analysis courses of ordinary colleges and universities_— Taking Guizhou Normal University as an example [J]. Shandong Chemical Industry, 2019, 48(17) ): 210-211.

2. Guo Huiqin, Li Kexin, Yan Liushui. The construction and practical thinking of "Environmental Analytical Chemistry" bilingual course of environmental engineering major in local undergraduate universities[J]. Journal of Nanchang Hangkong University (Natural Science Edition), 2018, 32(03): 111 -116.

3. Wang Guangrong, Ji Junxian. The innovation and practice of experiment teaching in colleges and universities based on Balabolka and Flash software_- Take the experimental teaching of analytical chemistry as an example [J]. University Chemistry, 2017, 32(10): 67-74. 